https://doi.org/10.26593/sentris.v2i1.4615.87-103

\title{
Globalisasi dan Penerimaan LGBTQ+ di ASEAN: Studi Kasus Budaya Boys' Love di Thailand
}

\author{
Yasmin Nur Habibah ${ }^{1}$, Januar Aditya Pratama², Mesagus Muhammad Iqbal ${ }^{3}$ \\ ${ }^{1}$ Fakultas Ilmu Sosial dan Ilmu Politik, Universitas Padjadjaran, Indonesia, yasmin18002@mail.unpad.ac.id \\ ${ }^{2}$ Fakultas Ilmu Sosial dan Ilmu Politik, Universitas Padjadjaran, Indonesia, januar18001@mail.unpad.ac.id \\ ${ }^{3}$ Fakultas Ilmu Sosial dan Ilmu Politik, Universitas Padjadjaran, Indonesia,mesagus18001@mail.unpad.ac.id
}

\begin{abstract}
ABSTRAK
Dorongan global terkait LGBTQ+ masih menghadapi banyak tantangan, terutama di kawasan-kawasan Timur, tak terkecuali di Asia Tenggara. Kebanyakan hukum nasional mengidentifikasi kelompok LGBTQ+ sebagai gangguan kejiwaan yang pantas diberi hukuman-hukuman tertentu. Fenomena ini tentu berdampak pada bagaimana masyarakat menerima kaum ini secara sosial. Menurut penelitian yang dilakukan Pew Research Center, penerimaan publik terkait gerakan LGBTQ+ telah meningkat sejak tahun 2002, bahkan di negara-negara yang dapat disebut cukup konservatif, tak terkecuali Thailand. Budaya yang menjadi aset industri, yaitu ladyboy atau wanita-pria (waria), juga menjadi indikasi penerimaan Thailand terhadap gerakan LGBTQ+. Kini, sejak tahun 2018, industri perfilman Thailand bertemakan Boys' Love (BL) mendapatkan banyak dukungan dari para pencinta film dan drama, khususnya di negara-negara ASEAN. Dalam tulisan ini, akan dibahas mengenai perkembangan budaya BL di Thailand, yang kemudian berpotensi memunculkan dampak terhadap penerimaan publik negara-negara anggota ASEAN terkait isu LGBTQ+. Berdasarkan analisis terhadap studi pustaka melalui perspektif teori queer, ditemukan bahwa budaya BL — yang kerap dipandang sebagai dampak globalisasi sosial-budaya — dapat menjadi kekuatan yang "memicu" fluiditas masyarakat dalam hal seksualitas, bahkan dalam lingkungan kultural Asia Tenggara yang dikenal konservatif.
\end{abstract}

Kata Kunci: ASEAN; Boys' Love; globalisasi; Thailand; queer

\section{ABSTRACT}

The global push for LGBTQ + still faces many challenges, especially in Eastern regions, and Southeast Asia is no exception. Most national laws identify LGBTQ + people as a psychiatric disorder who deserve certain penalties. This phenomenon certainly has an impact on how society accepts these people socially. According to research conducted by the Pew Research Center, public acceptance of the LGBTQ + movement has increased since 2002, even in countries that can be described as quite conservative, Thailand is no exception. The culture which became an industrial asset, namely ladyboys, is also an indication of Thailand's acceptance of the LGBTQ+ movement. Now, since 2018, the Thai film industry with the theme Boys' Love (BL) has received a lot of support from film and drama lovers, especially in ASEAN countries. In this paper, we will discuss the development of BL culture in Thailand, which then has the potential to have an impact on public acceptance of ASEAN member countries regarding $L G B T Q+$ issues. Based on the analysis with the queer theory perspective, it is found that $B L$ culture - which is often seen as the impact of socio-cultural globalization-can be a force that "triggers" the fluidity of society in terms of sexuality, even in the cultural environment of Southeast Asia which is known to be conservative.

Keywords: ASEAN; Boys' Love; globalization; Thailand; queer 


\section{Pendahuluan}

Seiring dengan pandemi COVID-19 yang memaksa banyak orang untuk tetap di rumah, tingkatan konsumsi hiburan digital pun semakin meningkat. Salah satu penyebabnya ialah panjangnya jangka waktu imbauan untuk tetap tinggal di rumah; menciptakan adanya permintaan untuk keberagaman dari konten hiburan yang bisa dinikmati oleh masyarakat. Dari periode yang lama dan permintaan yang meningkat itu, genre Boys' Love menemukan pasar yang semakin meluas. Genre Boys' Love sendiri berasal dari dari Jepang dengan manga, komik khas Jepang, dan anime, dengan serial animasi khas Jepang menjadi media penyebarannya. Dari manga dan anime Jepang, muncul ketertarikan terhadap budaya Boys' Love di Thailand, Tiongkok, Korea, serta negara-negara Asia lainnya; masing-masing mengadopsinya dengan melihat keadaan yang dihadapi oleh komunitas LGBTQ+ pada tiap-tiap negara. Melalui adopsi subkultur Jepang ke dalam literatur domestik dan adaptasi di layar kaca, jaringan Boys' Love pun berhasil menjadi fenomena di Asia dan dunia. ${ }^{1}$

Fenomena populernya Boys' Love di Thailand sendiri berasal dari keberhasilan serial 2gether, yang menceritakan perasaan antara dua pria muda. Dengan keberhasilan tersebut, baik produk sinema Thailand ataupun film bergenre Boys' Love, semakin sering diproduksi untuk memenuhi permintaan asing yang muncul. Genre yang semakin mengglobal ini-terutama di Asia—berhasil menarik perhatian karena unsur budaya yang dibawa, yaitu kehidupan LGBTQ+ yang merupakan suatu kontroversi tersendiri di lingkungan para penonton. ${ }^{2}$ Berkaitan dengan kontroversi keberadaan komunitas LGBTQ+, dalam televisi Thailand, keberadaan karakter homoseksual awalnya merupakan sesuatu yang janggal, apabila terdapat karakter atau hubungan homoseksual, biasanya ia bukanlah komponen inti dari alur cerita utama. Hal tersebut mulai berubah pada tahun 2007, yang mana Love of Siam dirilis dengan tema perasaan cinta antara dua lelaki muda selama di sekolah menengah atas. Keberadaan film tersebut mengundang reaksi yang besar dan menjadi keberhasilan yang tidak terduga. Kontroversi yang lebih besar pun mengikuti; namun, keberhasilan finansial film tersebut menandakan adanya permintaan dalam pasar romansa sesama jenis. $^{3}$

Lantas, terkait dengan kontroversi perluasan diversitas gender dan seksualitas ke ranah hiburan, debat akademik mengenai efek globalisasi terhadap identitas gender dan seksual pun bermunculan. Di satu sisi, terdapat argumen-argumen yang berupaya menunjukkan adanya upaya homogenisasi menuju budaya kebaratan yang liberal, seperti yang disimbolkan oleh "bendera pelangi" sebagai simbol representatif komunitas LGBTQ+. Di sisi lain, muncul pula penekanan mengenai ketahanan dari konsep-

\footnotetext{
${ }^{1}$ Koaysomboon, T. (2020, 11 Juni). Everything You Need to Know about Thailand's Thriving Boys Love Culture. Timeout. Diakses dari https://www.timeout.com/bangkok/lgbtq/thai-boys-love-culture (Diakses 10 Januari 2021).

2 Wira, N. N. (2020, 17 Juli). Rainbow-Colored Thai Dramas That Deserve Your Attention. The Jakarta Post, 17 Juli 2020. Diakses dari https://www.thejakartapost.com/life/2020/07/17/rainbow-colored-thai-dramas-that-deserve-your-attention.html

${ }^{3}$ Watson, J., dan Jirik, K. (2018, 16 Juni). Boys' Love: The Unstoppable Rise of Same-Sex Soapies in Thailand. ABC. Diakses dari https://www.abc.net.au/news/2018-06-16/boys-love-same-sex-dramas-inthailand/9874766\#: :text=In\%20recent\%20years\%20the\%20genre,normal\%20in\%20Thai\%20pop\%20culture
} 
89 Yasmin Nur Habibah, Januar Aditya Pratama, Mesagus Muhammad Iqbal | Globalisasi dan Penerimaan LGBTQ+ di ASEAN: Studi Kasus Budaya Boys' Love di Thailand

konsep lokal mengenai gender dan seksualitas, yang ditunjukkan oleh pergerakan global yang lebih beragam; ia lebih bersifat inklusif terhadap kategorisasi gender dan seksualitas lokal.

Bersamaan dengan perdebatan akibat semakin populernya genre Boys' Love (serta pengaruh sosial-budaya LGBTQ+ ada umumnya), penulis merasa bahwa masifnya genre Boys' Love di Thailand menjadi satu langkah lebih maju menuju penerimaan LGBTQ+ di kawasan Asia Tenggara, di mana selama ini cukup sulit diterima masyarakat akibat faktor budaya 'Timur' yang kurang progresif. Tulisan ini pun akan dimulai dengan pembeberan konteks LGBTQ+ di Asia, disusul dengan menelusuri perkembangan kultur Boys' Love itu sendiri. Selanjutnya, akan dibedah bagaimana kultur tersebut dapat berkembang melalui perspektif teori queer yang bersifat kritis. Pada akhirnya, pertanyaan yang mengemuka dan akan dijawab dalam tulisan ini ialah bagaimana dampak dari kultur Boys' Love terhadap penerimaan komunitas LGBTQ+ di Thailand dan juga negara-negara Asia Tenggara lainnya yang berdekatan secara geografis. Dampak ini dirasa oleh penulis akan menjadi signifikan ke depannya, sebagaimana penerimaan terhadap komunitas LGBTQ+ di Asia Tenggara masih tergolong rendah jika dibanding dunia Barat, dimana tak jarang hal ini turut memunculkan kejadian-kejadian persekusi terhadap orang-orang yang mengidentifikasikan dirinya sebagai demikian.

Untuk mencapai jawaban atas pertanyaan yang dihadirkan, tulisan ini akan menggunakan konsep global queering serta teori queer sebagai alat penganalisaan. Lalu, akan ditelusuri pula proyeksi arah tren penerimaan terhadap komunitas LGBTQ+ di negara-negara Asia Tenggara. Oleh karena itu, konklusi akan dihasilkan dari penelusuran yang mengandalkan metodologi deduktif, karena sejatinya akan tergambar apakah teori yang digunakan telah terrefleksikan dalam studi kasus yang dipilih.

\section{Landasan Konseptual dan Teoretis Konsep Global Queering}

Pada awalnya, kata queer sendiri memang berkaitan atau bermakna sama dengan kata "aneh" atau “abnormal". Namun, sejak tahun 1980-an, penyematan label queer bagi identitas homoseksual mulai dipergunakan dengan motivasi politis serta untuk alternatif identifikasi. ${ }^{4} \mathrm{Hal}$ tersebut turut dilakukan sebagai suatu bentuk perlawanan berupa provokasi, sebagaimana komunitas homoseksual kerap mendapat perlakuan yang tidak adil dari masyarakat pada umumnya. Ketimbang diam-diam saja dan membaur atau menutup-nutupi orientasi sosialnya, pada masa itu mereka memilih untuk mengidentifikasi diri sebagai queer; tujuan lainnya ialah untuk mempermudah urusan berserikat dengan sesama homoseksual. Sehingga, terbukalah jalan untuk dilakukannya aktivisme queer global.

Kemudian, Peter Jackson menyampaikan bahwa global queering merupakan konsep yang digunakan untuk menjelaskan tentang proliferasi dari diversitas gender dan seksualitas itu sendiri, dengan memprioritaskan adanya penerimaan terhadap komunitas LGBTQ+ di seluruh dunia. ${ }^{5}$ Sebagaimana aktivisme queer dimulai dari Amerika Serikat, ia pun bergerak meluas beriringan dengan arus globalisasi, terutama setelah adanya perkembangan pesat dalam teknologi komunikasi. ${ }^{6}$ Dengan begitu, ia dapat

\footnotetext{
${ }^{4}$ Kornak, J. (2015, 4 Februari). Queer as a Political Concept. Gender Studies, University of Helsinki. Diakses dari https://core.ac.uk/download/pdf/33732782.pdf

5 Jackson P. A. An Explosion of Thai Identities: Global Queering and Re-Imagining Queer Theory. Culture, Health \& Sexuality, 2(4), 405-424. 2000. DOI: 10.1080/13691050050174422

${ }^{6}$ Altman, D. Rupture or Continuity? The Internationalization of Gay Identities. Social Text, 48, 77-94. 1996. DOI: $10.2307 / 466787$
} 
90 Yasmin Nur Habibah, Januar Aditya Pratama, Mesagus Muhammad Iqbal | Globalisasi dan Penerimaan LGBTQ+ di ASEAN: Studi Kasus Budaya Boys' Love di Thailand

dikatakan sebagai salah satu kekuatan atau dampak globalisasi sosial-budaya, yang dipandang oleh sebagian sebagai "westernisasi". Selain itu, ia juga difasilitasi dengan adanya ruang diskursus dalam bidang gender dan seksualitas, terutama dalam dunia akademik. Alhasil, identitas serta aktivisme homoseksual serta transgender pun ikut merebak dalam peradaban-peradaban non-Barat, seperti Asia yang terkenal akan budayanya yang konservatif.

Dalam global queering sebagai agenda juga terdapat perlawanan terhadap pemikiran-pemikiran pro-homoseksual serta pro-transgender Barat yang cenderung menghomogenisasi pengalaman Barat kepada dunia non-Barat. ${ }^{7}$ Kemudian, Jackson juga mengritik persepsi bahwa munculnya queerness pada peradaban-peradaban non-Barat merupakan hasil dari "impor" budaya Barat semata. ${ }^{8}$ Padahal, tidak seluruh peradaban mengikuti model kategorisasi gender yang bersifat biner. Maka dari itu, agenda yang dibawakan oleh global queering tidak hanya terbatas pada penerimaan LGBTQ+; ia juga hirau terhadap penindasan pada umumnya, termasuk penindasan diskursif oleh suara akademik Barat, turut beririsan kepentingan dengan feminisme pascakolonial.

Pada akhirnya, konsep global queering dapat diartikan sebagai suatu pergerakan aktif dan juga dapat dipandang sebagai dampak dari globalisasi kultural. Terlepas dari perdebatan mengenai asalnya, pergerakan queer global setidaknya memiliki satu tujuan yang pasti: penerimaan komunitas LGBTQ+ (yang turut mencakup homoseksual serta transgender) ke dalam masyarakat. Meski begitu, dari global queering tersebut, masih terdapat pandangan-pandangan yang cukup berbeda, terutama antara aktivis queer dari Barat dengan yang non-Barat. Aktivisme queer non-Barat sendiri berupaya untuk meminimalisasi hegemoni Barat dalam pembentukan pengetahuan dalam diskursus gender dan seksualitas itu sendiri.

\section{Teori Queer}

Teori queer mulai populer pada setelah berakhirnya Perang Dingin, yang mana ia turut dicakup oleh studi Hubungan Internasional. Sehingga, teori queer sendiri dapat dipandang sebagai bagian dari gerakan pascapositivis dalam Hubungan Internasional, yang menolak akan keberadaan kebenaran objektif universal. Ia pun turut termasuk ke dalam kategori teori-teori kritis, yang melakukan penelusuran ulang terhadap pengetahuan konvensional. Dengan begitu, sejatinya, teori queer berupaya untuk mendekonstruksi pengetahuan. Salah satu contohnya adalah bagaimana teori queer serta aktivisme global queering kerap dikaitkan dengan politik identitas; nyatanya, menurut teori queer, identitas politik merupakan label yang merendahkan. ${ }^{9}$ Menurut para pemikir queer, identitas belum tentu merupakan sesuatu yang diinginkan pihak yang bersangkutan, dengan adanya identitas-identitas tertentu yang justru dipilih oleh aktor eksternal. Lalu, meskipun memiliki basis yang sama dengan teori-teori feminis, teori queer menjangkau lebih jauh dengan menghiraukan identitas serta aktivitas seksual yang berkaitan dengan status normalitas; teori queer juga melancarkan kritiknya terhadap feminisme yang dianggap terjebak dalam pemikiran biner tentang gender. ${ }^{10}$

\footnotetext{
7 Jackson. An Explosion of Thai Identities.

8 Ibid.

${ }^{9}$ Lewis, H. The Politics of Everybody: Feminism, Queer Theory, and Marxism at the Intersection. London: Zed Books, 2016.

${ }^{10}$ Rudy, K. Queer Theory and Feminism. Women's Studies, 29(1), 195-216. 2000. DOI: 10.1080/00497878.2000.9979308
} 
91 Yasmin Nur Habibah, Januar Aditya Pratama, Mesagus Muhammad Iqbal | Globalisasi dan Penerimaan LGBTQ+ di ASEAN: Studi Kasus Budaya Boys' Love di Thailand

Selanjutnya, teori queer dapat dijelaskan melalui dua jenis fokus, yaitu fokus konstruktivistis dan juga fokus metodologis. Pertama, dalam fokus konstruktivistis, teori queer menyorot pandangan bahwa gender merupakan konstruksi sosial. Pada umumnya, gender dipersepsikan secara biner, yakni laki-laki dan perempuan. Nyatanya, adanya kategorisasi sempit secara biner tersebut menciptakan opresi terhadap individu-individu yang mengidentifikasi dirinya dengan gender di luar kedua kategori gender konvensional tersebut. Seperti bahasan sebelumnya, hal tersebutlah yang turut memunculkan istilah queer itu sendiri. Lalu, ia juga mengritik akan adanya asumsi normalitas mengenai hal apa yang seharusnya dilakukan dan hal apa yang tidak seharusnya dilakukan dalam lingkup sosietal, yang mana asumsi tersebut juga merupakan konstruksi sosial. Bahkan, absolutisme naturalis juga termasuk ke dalam konstruksi sosial; banyak yang berargumen bahwa pada dasarnya, hewan (apabila berasumsi manusia juga merupakan bagian darinya) merupakan makhluk heteroseksual. Padahal, ditemukan bahwa hewan sejatinya merupakan makhluk yang biseksual. ${ }^{11}$

Kedua, secara metodologis, hasil akhir dari analisis teori queer tidak berakhir para hasil-hasil yang bersifat biner dan sempit. Berdasarkan teori queer, adanya pembatasan biner merupakan bentuk dari generalisasi yang berlebihan, layaknya pada kasus gender yang sebelumnya telah disebutkan. Layaknya teori-teori kritis lainnya, teori queer berusaha memupuk kesadaran akan eksistensi relasi kuasa dalam produksi serta distribusi pengetahuan. Dengan terminimalisasinya pemikiran-pemikiran yang biner serta adanya kesadaran akan relasi kuasa itu, diharapkan akan ada liberalisasi terhadap unsur-unsur masyarakat yang teropresi, terutama komunitas LGBTQ+. Bersamaan dengan sifatnya yang pascapositivis, teori queer menolak akan adanya klaim atas kebenaran tunggal yang bersifat universal, sebagaimana ia merupakan hasil relasi kuasa dan berpotensi menindas pihak-pihak tertentu.

Akan tetapi, akibat tidak adanya pembatasan secara ontologis dan epistemologis, teori queer pun turut mendapat kritik, yang kerap menyebut teori queer sebagai ambisius dan penuh paradoks. ${ }^{12}$ Hal tersebut juga berdampak pada ketiadaan akan definisi tunggal atau universal teori queer itu sendiri, karena apabila definisi tersebut ada, tentunya bertentangan dengan nilai-nilai yang dibawa. Walau demikian, diargumentasikan bahwa adanya keberagaman dalam teori-teori queer itu sangatlah sesuai dengan karakteristik studi Hubungan Internasional yang luas dan juga beragam. Selain itu, adanya pengekangan terhadap perkembangan pengetahuan pun dipersepsikan sebagai ancaman yang dapat menghambat perkembangan teori queer. Oleh karenanya, teori queer bersifat terbuka akan adanya keberagaman pemikiran.

\section{Analisis}

\section{Konteks Perkembangan LGBTQ+ di Asia}

Sejak Hillary Clinton mengenalkan istilah LGBT di tahun 2011, berbagai organisasi internasional dan regional-seperti PBB dan Uni Eropa-mulai menunjukkan dukungannya dengan mengeluarkan dokumen resmi, terutama terkait perlindungan pada hak kaum LGBT; begitu pula dengan negara-negara yang tergolong liberal, seperti Amerika Serikat. Namun, jauh sebelum fenomena ini muncul, Kees Waaldjik di tahun 1994 mengatakan bahwa kemunculan ide baru dalam konteks identitas bukannya

\footnotetext{
${ }^{11}$ Hogenboom, M. (2015, 6 Februari). Are There Any Homosexual Animal? BBC. Diakses dari http://www.bbc.com/earth/story/20150206-are-there-any-homosexual-animals

12 Jagose, A. Feminism's Queer Theory. Feminism \& Psychology, 19(2), 157-174. 2009. DOI: 10.1177/0959353509102152
} 
92 Yasmin Nur Habibah, Januar Aditya Pratama, Mesagus Muhammad Iqbal | Globalisasi dan Penerimaan LGBTQ+ di ASEAN: Studi Kasus Budaya Boys' Love di Thailand

berjalan tanpa masalah; dalam banyak kasus, disebutkan bahwa negara-negara terkadang "mengambil langkah mundur". Maksud dari pernyataannya ini mengarah pada tren kemajuan secara umum: di mana ada perubahan hukum, maka itu adalah perubahan yang lebih baik. Sayangnya, tidak semua negara bergerak pada waktu serta momentum yang sama dan tentunya tidak dengan kecepatan yang sama. ${ }^{13}$

Di negara-negara Asia Tenggara, seperti di Singapura, Malaysia dan Indonesia, aktivisme LGBT yang telah berkembang tampak sangat berbeda dengan yang ditemukan di sebagian besar negara-negara Barat, karena terdapat sejumlah pertimbangan penting. Salah satunya ialah asumsi tentang aktivisme LGBT dan evolusi globalnya perlu dipertanyakan ketika menyelidiki konteks non-Barat. ${ }^{14}$ Tindakan seksual sesama jenis juga berpotensi mendapat hukuman, terutama di Malaysia, Singapura, Brunei Darussalam, begitu pula di Provinsi Sumatera Selatan dan Nanggroe Aceh Darussalam di Indonesia. Hanya ada satu negara di kawasan tersebut yang melindungi warganya dari persekusi serta diskriminasi berbasis gender dan identitas atau orientasi seksual di bawah hukum nasional, yaitu Thailand, yang sudah menerapkannya sejak tahun 2015. Terlepas dari perbedaan nilai budaya, kekerabatan, ikatan keluarga, dan pernikahan yang memiliki corak khusus, tidak ada tempat di Asia Tenggara yang mengakui hubungan sesama jenis dan tindakan adopsi bersama oleh pasangan lesbian dan gay secara hukum; membuka kemungkinan lebih besar untuk terjadinya persekusi dan diskriminasi.

Kemudian, kebanyakan kasus persekusi dan diskriminasi terhadap komunitas LGBTQ+ dan anggotanya di Asia Tenggara dikaitkan dengan tingginya angka gangguan kejiwaan, yang mana anggota komunitas LGBTQ+ kerap dianggap sebagai pengidap gangguan kejiwaan. Selain stigma kelainan kejiwaan, diskriminasi terhadap kaum LGBTQ+ kerap terjadi di wilayah yang secara ketat mengikuti keyakinan agama tertentu sebagai pedoman hukum, seperti hukum Syariah atau hukum Kristen berdasarkan Alkitab; dua negara yang paling terlihat dalam bentuk diskriminasi tersebut adalah Indonesia dan Filipina ${ }^{15}$. Hal tersebut merefleksikan akan sulitnya kaum LGBTQ+ untuk diterima oleh masyarakat dan negara di Asia Tenggara, walaupun kita ketahui bersama bahwa proses globalisasi tidak dapat menutup kemungkinan memengaruhi pandangan tersebut. Selain itu, terdapat pula budaya-budaya yang lebih inklusif, meski tidak sepenuhnya, terhadap seksualitas dan gender nonbiner, salah satunya Thailand.

\section{Penerimaan LGBTQ+ di Thailand}

Tentang penerimaan terhadap komunitas LGBTQ+ di Thailand, menurut Ojanen, setidaknya terdapat beberapa identifikasi gender dan seksualitas lain di luar gender biner serta heteroseksualitas: kathoey, gay, bi, tom, dee, les, dan bi. ${ }^{16}$ Patut dicatat bahwa berbeda dengan pemahaman Barat, konsepsi gender dan seksualitas di Thailand tidaklah secara utuh terpisah, melainkan kerap tercampur-adukkan. ${ }^{17}$

\footnotetext{
${ }^{13}$ Wilkinson, C., Gerber, P., Offord, B., dan Langlois, A. J. LGBT Rights in Southeast Asia: One Step Forward, Two Steps Back? IAFOR Journal of Asian Studies, 3(1), 5-17. 2017. DOI: 10.22492.ijas.3.1.01.pdf

${ }^{14}$ Collins, A. A people-oriented ASEAN: A door ajar or closed for civil society organisations? Contemporary Southeast Asia, 30(2), 313-331. 2008. DOI:10.1335/CS30-2G

15 Adihartono dan Jocson. A Comparative Analysis. Journal of Southeast Asian Human Rights, 4(1), 271-305. 2020. DOI: 10.19184/jseahr.v4i1.12810

${ }^{16}$ Ojanen, T. T. Sexual/Gender Minorities in Thailand: Identities, Challenges, and Voluntary-Sector Counseling. Sex Res Soc Policy, 6(2). 4-34. 2009. DOI: 10.1525/srsp.2009.6.2.4

${ }^{17}$ Hamilton, A. Genders and Sexualities in Modern Thailand. SOJOURN: Journal of Social Issues in Southeast Asia, $16(2), 331$. 2001. Diakses dari
} 
93 Yasmin Nur Habibah, Januar Aditya Pratama, Mesagus Muhammad Iqbal | Globalisasi dan Penerimaan LGBTQ+ di ASEAN: Studi Kasus Budaya Boys' Love di Thailand

Adanya identifikasi gender dan seksualitas lain di luar kategorisasi biner konvensional menunjukkan akan adanya keberagaman dalam gender dan seksualitas itu sendiri dalam masyarakat Thailand, meskipun identitas-identitas tersebut juga mengalami opresi pada tingkat tertentu. Beberapa bentuk dari opresiopresi terhadap minoritas tersebut ialah pengakuan secara hukum, diskriminasi, dan minimalnya fasilitasi kesehatan fisik dan mental. Akan tetapi, patut diakui pula bahwa telah ada peningkatan taraf kehidupan bagi para minoritas tersebut di Thailand. Peningkatan itu muncul akibat adanya proses reimajinasi dari gender dan seksualitas di Thailand, yang menjadi lebih terbuka dan tidak kaku pada kategorisasi biner semata. $^{18}$

Jauh sebelum kultur Boys' Love, menurut Witchayanee Ocha, adanya penerimaan serta pengakuan terhadap identitas gender di luar kategorisasi biner terjadi dengan adanya perdagangan seks sebagai fondasi. ${ }^{19}$ Walau awalnya dianggap sebagai pekerjaan yang memalukan, nyatanya kini banyak di antara para pelaku perdagangan tersebut menjadi bangga atas kualitas atau taraf servis yang mereka berikan. Ditambah lagi dengan adanya kemajuan teknologi medis, akan menjadi lebih mudah bagi individu-individu seks tertentu untuk berpindah identitas menuju sex lainnya. Sehingga, tingkat operasi transseksual pun menjadi tinggi, dengan satu dari 25.000 individu kelahiran laki-laki dan satu dari

100.000 kelahiran perempuan melakukan operasi tersebut. ${ }^{20}$ Alhasil, populasi transgender pun semakin merebak di Thailand, beriringan dengan peningkatan identitas seksualitas lainnya selain heteroseksualitas; menjadikan adanya gender dan seksualitas lain lebih "normal", setidaknya dengan meningkatkan frekuensi kehadirannya di tengah masyarakat. Dengan begitu, terbukalah jalan bagi gender-gender lain untuk berkecimpung atau bekerja di luar bidang perdagangan jasa seksual, salah satunya ialah pada sektor media yang turut memunculkan kultur Boys' Love.

\section{Proses Globalisasi Kultur Boys' Love}

Genre Boys' Love Thailand sendiri sebenarnya diadaptasi dari Jepang dengan manga, komik khas Jepang, dan anime, dengan serial animasi khas Jepang menjadi media penyebarannya. Dari manga dan anime Jepang, muncul ketertarikan terhadap budaya Boys' Love di Thailand, Tiongkok, Korea, dan negara asia lainnya; masing-masing mengadopsinya dengan melihat keadaan yang dihadapi oleh komunitas LGBTQ+ pada tiap-tiap negara. Boys' Love diyakini oleh Fujimoto Yukari, Profesor dari Meiji University, sebagai manga (komik) yang menceritakan kisah cinta antara laki-laki remaja yang disebut shōnen-ai. ${ }^{21}$ Memang, manga tersebut ditujukan untuk dikonsumsi perempuan. Pada awalnya manga untuk perempuan ditulis oleh komikus laki-laki. Kemudian, muncul gelombang seniman perempuan yang lahir pasca perang pada akhir dekade 1960-an yang dapat lebih mewakil demografi konsumennya. Penggunaan karakter utama perempuan menjadi kelaziman dari manga yang ditujukan untuk perempuan.

https:/go.gale.com/ps/anonymous?id=GALE\%7CA79663153\&sid=googleScholar\&v=2.1\&it=r\&linkaccess=abs\&issn=0217952 $0 \& \mathrm{p}=\mathrm{AONE} \& \mathrm{sw}=\mathrm{W}$

18 Ocha, W. Transsexual Emergence: Gender Variant Identities in Thailand. Culture, Health \& Sexuality, 14(5), 563-575. 2012. DOI: $10.1080 / 13691058.2012 .672653$

19 Ibid.

${ }^{20}$ Chokrungvaranont, P. dan Tiewtranon, P. Sex Reassignment Surgery in Thailand. Journal of the Medical Association of Thailand, 87(11). 2004. Diakses dari https://www.researchgate.net/publication/7910718_Sex_reassignment_surgery_in_Thailand ${ }^{21}$ Yukari, F. (2020, 24 September). The Evolution of "Boys' Love" Culture: Can BL Spark Social Change? Nippon. Diakses dari https://www.nippon.com/en/in-depth/d00607/ 
94 Yasmin Nur Habibah, Januar Aditya Pratama, Mesagus Muhammad Iqbal | Globalisasi dan Penerimaan LGBTQ+ di ASEAN: Studi Kasus Budaya Boys' Love di Thailand

Namun, karakter wanita yang digambarkan terlalu dibatasi, karena mencerminkan kondisi sosial perempuan pada masa tersebut.

Kemudian, kemunculan serta perkembangan unsur budaya Boys' Love ini dipahami sebagai bagian dari keingintahuan masyarakat akan pengetahuan seksual yang mana tayangan-tayangan berbasis BL mampu memberikan imajinasi alternatif dari perkembangan pengetahuan modern. ${ }^{22}$ Baru-baru ini drama televisi BL Thailand pun terlihat mendapatkan banyak pengikut di seluruh dunia, misalnya seri 2gether, yang menyajikan kisah cinta dua mahasiswa laki-laki. Tayangan ini baru saja memenangkan banyak penggemar dengan saluran YouTube resmi yang sudah difasilitasi teks bahasa Inggris - bahkan menduduki puncak daftar tren global Twitter di pertengahan 2020.

Uniknya lagi, banyak akademisi dan budayawan Jepang yang melihat bahwa Thailand telah membentuk pola BL-nya sendiri, terutama setelah adanya pengakuan hukum resmi pasangan gay di Thailand yang diizinkan mengadopsi anak dan mewariskan warisan. Tindakan tersebut juga merupakan dampak tidak langsung dari pemasukan besar yang Thailand terima dari industri perfilman BL sejak 2007. Jauh sebelum seri 2gether, Love of Siam (2007) telah mulai mencuri perhatian khalayak internasional dengan menghasilkan keuntungan dua juta dolar Amerika. Walaupun saat itu statusnya masih terselubung dan kontroversial, kesuksesan film ini memberikan pesan yang tegas kepada perusahaan hiburan Thailand bahwa ada uang yang dapat dihasilkan dari romansa beraroma LGBTQ+, spesifikasinya gay. ${ }^{23}$ Setelah 10 tahun, tepatnya tahun 2017, budaya ini sedikit demi sedikit menjadi hal normal dalam budaya populer Thailand, bahkan memicu perubahan mendasar bagi masyarakat (terutama anak muda) Thailand. Walaupun ada kesadaran status hukum yang ilegal pada fenomena ini, setidaknya masyarakat bersikap lebih toleran terhadap mereka para nonheteroseksual.

Selain Love of Siam, Love Sick the Series (2014) yang diputar di Saluran 9 Thailand dan diinisiasi oleh Organisasi Komunikasi Massa Thailand (MCOT) menjadi titik puncak globalisasi kultur BL ke seluruh dunia, terutama Tiongkok dan negara-negara Asia lain. ${ }^{24}$ Kesuksesan besar Love Sick sebagai sebuah serial diukur dari 3.753 .178 penayangan di YouTube dan 300.176 pengikutnya di halaman Facebook resmi dari serial tersebut per 9 Oktober 2019 dan berhasil membuka gerbang baru untuk adaptasi-adaptasi lain dari novel BL Thailand di layar lebar. ${ }^{25}$ GMM Grammy Company boleh dibilang menjadi perusahaan dengan tender tertinggi di Thailand saat ini yang berhasil melakukan perluasan layar industri televisi Thailand menjadi sepenuhnya menganut konten yaoi atau kultur BL.

Jika kita meninjau popularitas BL Thailand di Asia Tenggara, kemungkinan besar banyak faktor yang turut mendukung. Pertama, kultur ini berbentuk romansa, dan romansa telah terbukti populer secara universal dan dapat diakses selama ribuan tahun dalam pembuatan mitos dan penceritaan. Pembaca dapat memilih cerita yang paling sesuai dengan preferensi mereka, dari cerita yang tidak lebih dari pegangan tangan hingga cerita yang merinci tindakan seksual eksplisit, dalam berbagai pengaturan, dari yang

\footnotetext{
22 Baudinette, T. Lovesick, The Series: Adapting Japanese 'Boys Love' to Thailand and the Creation of a New Genre of Queer Media. South East Asia Research, 27(2), 115-132. 2018. DOI:10.1080/0967828X.2019.1627762

${ }^{23}$ Watson, J., dan Jirik, K. (2018, 16 Juni). Boys' Love: The Unstoppable Rise of Same-Sex Soapies in Thailand. ABC. Diakses dari https://www.abc.net.au/news/2018-06-16/boys-love-same-sex-dramas-inthailand/9874766\#: :text=In\%20recent\%20years\%20the\%20genre,normal\%20in\%20Thai\%20pop\%20culture

24 Yuqiao, J. (2020, 3 Agustus), Thai BL Drama Sweeps China, Improving Cultural Communication between Countries. Global Times. Diakses dari https://www.globaltimes.cn/content/1181965.shtml

${ }^{25}$ Watson dan Jirik. Boys' Love.
} 
95 Yasmin Nur Habibah, Januar Aditya Pratama, Mesagus Muhammad Iqbal | Globalisasi dan Penerimaan LGBTQ+ di ASEAN: Studi Kasus Budaya Boys' Love di Thailand

fantastis hingga yang mengerikan hingga yang kontemporer atau biasa. ${ }^{26}$ Jelas orang-orang di Asia Tenggara menerima genre ini. Kedua, kultur BL sama-sama bersifat menyentuh pembaca atau penonton dengan sajian yang unik, yaitu bentuk fiksi penggemar yang didedikasikan untuk hubungan homoerotik pria-pria. Kisah seperti ini memberikan dampak dan respon yang berbeda bagi setiap orang. Ketiga, BL pun dianggap "lebih baik daripada romansa biasa" dengan mengesampingkan identifikasi dan stereotip berbasis gender - topik yang sedang banyak dibahas dunia saat ini. ${ }^{27}$

Akan tetapi, meskipun BL populer secara transnasional (menuju global), sekali lagi, BL adalah genre yang relatif baru dan tidak biasa di ASEAN. Pastinya komoditas ini perlu terus disesuaikan agar dapat bertahan. Kini, digitalisasi semakin mendukung penyebaran kultur BL Thailand. Melalui mediamedia yang mudah diakses, seperti YouTube dan Twitter, bahkan media-media berbayar sekali pun, setiap orang dapat menikmati sajian drama BL. Meskipun hal-hal berbau LGBTQ+ menjadi hal yang tabu di negara-negara Asia Tenggara, menonton drama ini setidaknya mengarahkan atau memberi perspektif baru bagi masyarakat perkotaan terkait penerimaan yang lebih dalam pada kaum LGBTQ+.

Dengan begitu, apabila dikaitkan dengan teori queer, maka yang terjadi ialah rekonstruksi pemahaman mengenai gender dan seksualitas itu sendiri, entah di Thailand, maupun negara-negara lain yang terpapar kultur BL dari Thailand. Mulai dari pemahaman tradisional yang cenderung heteroseksual dan biner, kini Thailand telah lebih memahami serta mengakui akan adanya gender-gender serta seksualitas lain. Sehingga, pada akhirnya, heteroseksualitas dan gender yang bersifat binerik kaku nyatanya hanyalah konstruksi sosial semata, sebagaimana telah tercerminkan bagaimana adanya fluiditas gender dan seksualitas dalam kehidupan masyarakat Thailand, terutama adanya normalisasi setelah populernya kultur Boys' Love. Dimulai dengan adanya pengakuan mengenai fluiditas gender dan seksualitas, maka penerimaan dan penyetaraan pun menjadi lebih realistis untuk dicapai bagi komunitas LGBTQ+ di Thailand. Selain itu, dengan adanya globalisasi kultur dan juga media massa transnasional, pengakuan serta penerimaan Boys' Love ini juga berpotensi menyebabkan adanya rekonstruksi pemahaman gender dan seksualitas di negara-negara lain, terutama yang memang menikmati karya media Thailand itu sendiri. Proses serta implikasi globalisasi kultur Boys' Love di Thailand terhadap penerimaan LGBTQ+ pada negara-negara tetangganya akan dibahas pada bagian-bagian berikutnya.

\section{Implikasi Globalisasi Kultur BL Thailand terhadap Penerimaan LGBTQ+ di Asia Tenggara}

Globalisasi kerap memiliki efek yang dianggap bertolak belakang bagi pergerakan LGBTQ+. Di satu sisi, globalisasi memungkinkan adanya pergerakan, tetapi di sisi lainnya globalisasi memunculkan penolakan terhadapnya. Perkembangan komunikasi dan keterhubungan memunculkan kemungkinan baru dalam solidaritas internasional dengan media komunikasi elektronik menyediakan alat bagi pergerakan LGBTQ+ untuk bergerak secara senyap. Internet pun menjadi media yang penting dalam penyebaran pesan. Dengan aspek-aspek kultural, seperti munculnya film dan serial dengan unsur LGBTQ+, terlihat

\footnotetext{
${ }^{26}$ Prasannam, N. The Yaoi Phenomenon in Thailand and Fan/Industry Reaction. Plaridel Journal, 16(2), 63-89. 2019. http://www.plarideljournal.org/wp-content/uploads/2019/12/2019-02-Prasannam.pdf

${ }^{27}$ Baudinette. Lovesick.
} 
96 Yasmin Nur Habibah, Januar Aditya Pratama, Mesagus Muhammad Iqbal | Globalisasi dan Penerimaan LGBTQ+ di ASEAN: Studi Kasus Budaya Boys' Love di Thailand

dengan pergerakan pro-LGBTQ+ yang lebih mendapat kemajuan ketimbang kemunduran, salah satunya melalui persebaran kultur seperti Boys' Love.

Kehadiran tayangan drama bertemakan Boys' Love seperti membawa angin segar bagi mereka, para kaum LGBTQ+. Spesifiknya di Asia, kaum ini belum mendapatkan tempat yang semestinya akibat perbenturan budaya dan keyakinan, terutama di kawasan Asia Tenggara. Sebuah survei dari Vice menyebutkan bahwa kehadiran drama BL mampu membuat apa yang mereka rasakan sebagai kaum LGBTQ+ dianggap. ${ }^{28}$ Salah satu yang diwawancarai langsung oleh tim vice adalah pemuda asal Indonesia, di mana ia menyebutkan statusnya sebagai muslim yang jelas terlarang memiliki orientasi seksual yang menyimpang, salah satunya sebagai seorang biseksual.

Hal ini pun sama terjadi di negara-negara lain, bahkan Tiongkok, yang tampaknya sudah mengangkat drama-drama bertema serupa sebelum popularitas BL Thailand naik. Di Tiongkok, 2016 menjadi awal popularitas BL Thailand dengan sebuah drama berjudul, "Addicted". Acara tersebut memperoleh sepuluh juta tampilan per harinya setelah perilisan awal. Namun sayangnya, serial ini ditarik dari media streaming iQiyi (salah satu media hiburan besar dari Tiongkok), tiga hari sebelum episode ke15 dan terakhir ditayangkan. Hal ini disebabkan karena faktor politik Tiongkok yang cukup tertutup dengan produk-produk asing, ditambah dengan penerimaan terhadap LGBTQ+ yang belum disuarakan secara merata. Uniknya, para penggemar kemudian mengunggah episode dengan terjemahan bahasa Mandarin ke YouTube, di mana hingga awal tahun 2020, tayangan tersebut memiliki rata-rata 500.000 penayangan per harinya. ${ }^{29}$ Secara tidak langsung, kesukaan para penggemar terhadap tayangan $\mathrm{BL}$ Thailand mendorong keyakinan para warga untuk menerima keberadaan kaum dan bahkan memprovokasi mereka untuk berpikir out-of-the-box.

Lalu, penulis akan berlanjut ke studi kasus lain, yaitu Filipina. Seperti yang Prasannam dan Baudinette sebutkan dalam jurnalnya, Filipina adalah negara penganut Katolik terbesar di Asia Tenggara. ${ }^{30}$ Dalam penafsiran Katolik, hubungan sesama jenis merupakan larangan, layaknya apa yang negara-negara islam terapkan. Maka dari itu, tidak heran apabila drama-drama Filipina selalu menampilkan romansa heteroseksual layaknya genre di Hollywood secara umum ${ }^{31}$, yang uniknya selalu diperankan oleh para aktor dan aktris yang berhubungan di dunia nyata. Paham tersebut pun menjadi bentuk adaptasi dari keyakinan Katolik yang percaya bahwa hubungan antara manusia haruslah menjunjung rasa setia dan loyal. Dalam kasus BL Thailand sendiri, di awal tahun 2020, media hiburan terbesar Filipina-ABS-CBN-menambahkan serial 2gether dan Hormones ke dalam tayangan nasionalnya. Hal ini tentu menjadi sebuah kemajuan, karena biasanya drama-drama berbau LGBTQ + hanya ditayangkan di televisi kabel berbayar, mendapatkan akses di YouTube pun merupakan keberuntungan tersendiri bagi warga Filipina. ${ }^{32}$ Kemajuan lain di Filipina pun ditunjukkan dengan drama BL versi Filipina yang akan tayang di awal 2021 berjudul, "Hello, Strangers". Namun, belum ada penelitian maupun informasi terbaru terkait dengan sikap pemerintah Filipina mengenai penerimaan publik

\footnotetext{
${ }^{28}$ Guzman, C. (2020, 17 Juni). Boys' Love: The Gay Romance TV Genre Taking Over Southeast Asia. VICE. Diakses dari https://www.vice.com/en/article/qj4k55/boys-love-tv-asia-trend-lgbtq-2gether

29 Ibid.

${ }^{30}$ Prasannam. Yaoi Phenomenon; Baudinette. Lovesick.

31 Ibid.

32 Guzman. Boys' Love.
} 
97 Yasmin Nur Habibah, Januar Aditya Pratama, Mesagus Muhammad Iqbal | Globalisasi dan Penerimaan LGBTQ+ di ASEAN: Studi Kasus Budaya Boys' Love di Thailand

domestik terkait $\mathrm{LGBTQ}^{+}$, termasuk respon pemerintah terkait laporan yang dibuat UNDP pada tahun 2013.

Berbeda dengan negara-negara lain, di Thailand, hangatnya isu LGBTQ+ tidak hanya datang dari sektor industri hiburan, melainkan didorong pula oleh peningkatan jumlah komunitas LGBTQ+ selama lima tahun terakhir. Dalam cakupan internal Thailand sendiri, kemunculan kelompok-kelompok tersebut didukung oleh Jaringan Advokasi Transnasional (JAT), seperti Rainbow Sky Association, Foundation for SOGI Rights and Justice (FOR-SOGI), Anjana Suvarnananda, dan Purple Sky. ${ }^{33}$ Kelompok ini memiliki tekad untuk memperjuangkan hak para anggota kelompok LGBTQ+ sekaligus melindungi mereka dari tindakan-tindakan diskriminatif. Sejak popularitas drama BL di tahun 2007, Thailand telah banyak melakukan revisi dan adopsi hukum terkait perlindungan kaum-kaum minoritas, yang termasuk di dalamnya kaum LGBTQ+. Sebelumnya, laporan dari UNDP menyatakan bahwa-baik secara konstitusi, penerimaan sosial, dan relevansi agama-Thailand tidak sepenuhnya menerima minoritas seksual dan gender. ${ }^{34}$ Sikap terhadap individu LGBT dapat bertahan pada batas ambang toleran selama para LGBT tetap berada dalam batasan sosial tertentu. Bagi mereka yang bersikap tertutup, biasanya mendapatkan tantangan jauh lebih besar di level keluarga. Secara singkat, keluarga-keluarga di Thailand menganggap keberadaan anggota berorientasi seksual menyimpang merupakan aib.

Akan tetapi, sejak tahun 2020, Kabinet Thailand telah menyetujui rancangan undang-undang yang secara hukum akan mengakui kemitraan sipil sesama jenis dan memberikan hak yang lebih besar kepada pasangan sesama jenis. Jika terdapat keberlanjutan proses ratifikasi RUU tersebut oleh parlemen, maka Thailand akan menjadi tempat kedua di Asia yang mengizinkan pendaftaran perkawinan sesama jenis setelah Taiwan melegalkan pernikahan sesama jenis pada tahun 2019. ${ }^{35}$ Meskipun tidak sejauh mendukung pernikahan sesama jenis, RUU Kemitraan Sipil Thailand memungkinkan pasangan sesama jenis untuk mendaftarkan status mereka secara resmi. Di bawah RUU tersebut, pasangan sesama jenis dapat mengadopsi anak, mengklaim hak waris, dan bersama-sama mengelola aset seperti properti untuk pertama kalinya. Tentu, tindakan Thailand menjadi sebuah inovasi besar, mengingat negara ini cukup konservatif mengenai konstitusi dan hukum. Tindakan ini pun kemungkinan besar merupakan respon atas aksi demo prodemokrasi besar-besaran di Thailand pada pertengahan 2020 kemarin, yang mana salah satu agenda yang disuarakan mahasiswa adalah mengenai nasib kaum LGBTQ+. Banyak masyarakat yang menginginkan raja untuk mengurangi tindakan intervensinya terhadap politik Thailand, dan menyebutkan gerakan ini sebagai the new taste of Thai politics. ${ }^{36}$

Hebatnya lagi mengenai BL Thailand, genre ini telah mendapatkan hati banyak penonton drama di Asia Tenggara, tak terkecuali negara-negara anti-LGBT seperti Indonesia, Singapura, Malaysia, Brunei Darussalam, dan Timor Leste. Namun faktanya, sistem, sikap, keyakinan, perasaan, dan perilaku negatif terhadap lesbian, lelaki gay, dan sesama jenis (homonegativitas) masih menjadi bagian dari iklim stigma sosial yang dihadapi oleh minoritas seksual dan gender di wilayah-wilayah tersebut. Keberhasilan BL

\footnotetext{
33 Tyas, I. Upaya Transnational Advocacy Networks dalam Mendorong Legalisasi LGBT Rights di Thailand. Jurnal Hubungan Internasional, 8(1), 61-73. 2019. DOI: 10.18196/hi.81145

${ }^{34}$ UNDP (2014). Being LGBT in Asia: Thailand Country Report. Diakses darihttps://www.refworld.org/pdfid/54ed82784.pdf

${ }^{35}$ Regan, H. dan Olarn, K. (2020, 9 Juli). Thailand Could Become the First Southeast Asian Country to Legalize Same-Sex Civil Partnerships. CNN. Diakses dari https://edition.cnn.com/2020/07/09/asia/thailand-same-sex-union-bill-intl-hnk/index.html ${ }^{36}$ Ibid; Chen, D. (2020, 23 November). LGBTQ support lends 'new taste' to Thai Politics. The Jakarta Post. Diakses dari https://www.thejakartapost.com/seasia/2020/11/23/lgbtq-support-lends-new-taste-to-thai-politics-.html
} 
98 Yasmin Nur Habibah, Januar Aditya Pratama, Mesagus Muhammad Iqbal | Globalisasi dan Penerimaan LGBTQ+ di ASEAN: Studi Kasus Budaya Boys' Love di Thailand

Thailand dengan rating positif 98\% dari seluruh dunia dan hampir 3,9 juta penggemarnya di Asia Tenggara tidak serta merta menghapus sikap dan mengubah pandangan masyarakat umum terkait LGBTQ+. Negara-negara di Asia Tenggara masih dan akan terus dihadapi dengan tantangan baru sebagaimana kita ketahui bahwa menerima perbedaan merupakan gerakan dari naluri pribadi. Namun, tidak dapat dipungkiri bahwa arus globalisasi yang tinggi menyebabkan tayangan-tayangan seperti ini tidak terbendung dan pasti dapat menembus pasar masyarakat, karena sejatinya dunia maya tidak memiliki batasan. Oleh karena itu, peneliti LIPI, Ranny Rastati, pun melihat fenomena ini sebagai peluang bagi pemerintah, pihak swasta, dan bahkan kelompok-kelompok kecil berbentuk fandom untuk membentuk ekosistem pertukaran budaya pop antara Thailand dan negara-negara di Asia Tenggara. ${ }^{37}$ Improvisasi dan pengembangan upaya pun akan memperjelas posisi tayangan BL Thailand sebagai salah satu penggerak transnasional yang mampu mendorong penerimaan publik terkait dengan isu LGBTQ+ .

Sebagai pembanding, berikut perkembangan penerimaan terhadap komunitas LGBTQ+ di Asia Tenggara, yang tercakup dalam Indeks Penerimaan Global (GAI) oleh Williams Institute ${ }^{38}$ :

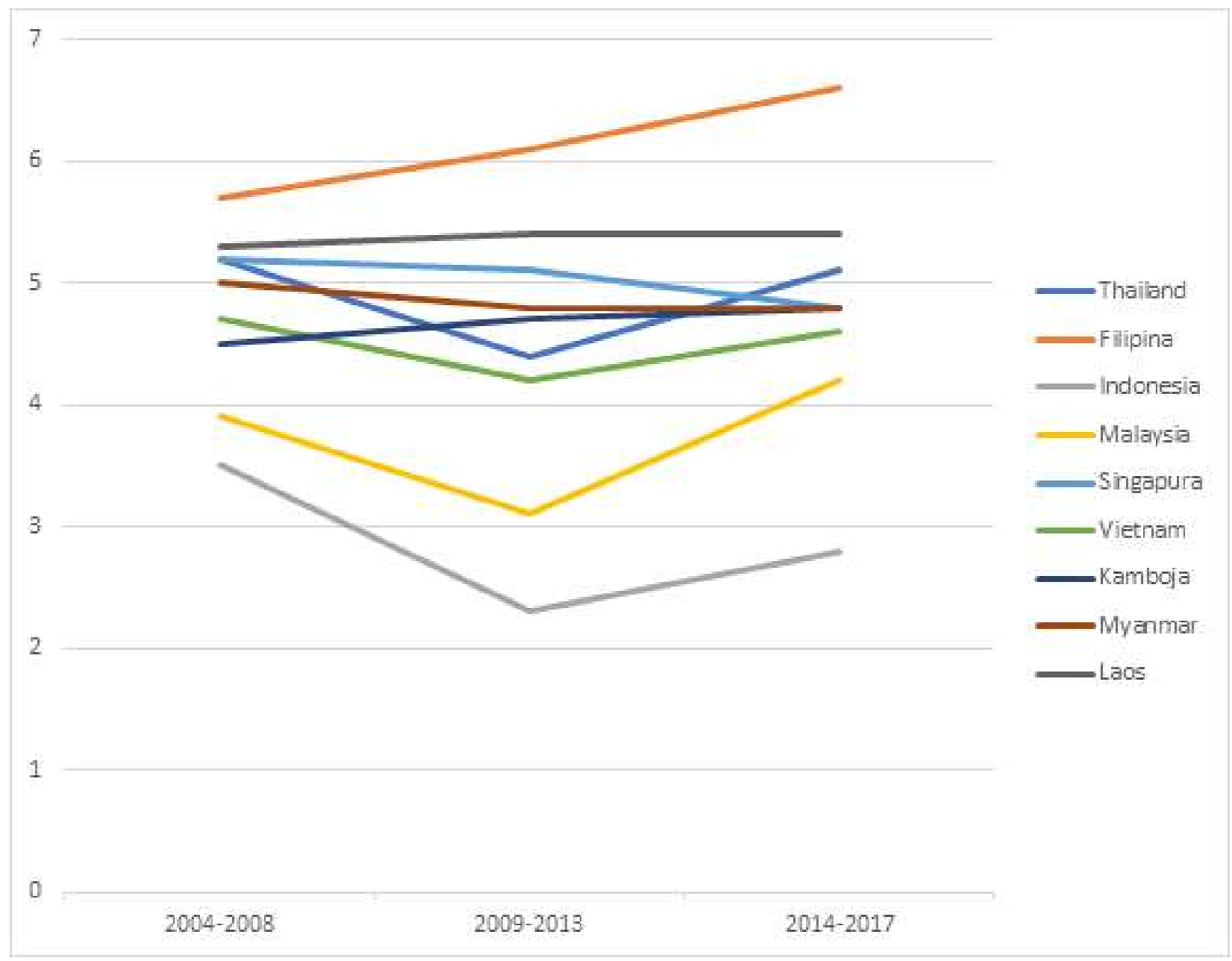

${ }^{37}$ Rastati, R. (2020, 31 Desember). Naiknya Thai Pop Culture dan Masa Depan Indonesian Pop (Indo Pop). LIPI. Diakses dari https://pmb.lipi.go.id/naiknya-thai-pop-culture-dan-masa-depan-indonesian-pop-indo-pop/

${ }^{38}$ Flores, A. R. Social Acceptance of LGBT People in 174 Countries. Williams Institute UCLA School of Law. 2019. https://williamsinstitute.law.ucla.edu/wp-content/uploads/Global-Acceptance-Index-LGBT-Oct-2019.pdf 
99 Yasmin Nur Habibah, Januar Aditya Pratama, Mesagus Muhammad Iqbal | Globalisasi dan Penerimaan LGBTQ+ di ASEAN: Studi Kasus Budaya Boys' Love di Thailand

Dapat dilihat bagaimana hanya terdapat dua negara yang mengalami tren positif menuju penerimaan komunitas LGBTQ+ secara signifikan, yaitu Filipina dan Kamboja. Kemudian, terdapat Laos yang sedikit meningkat dan lebih menggambarkan kondisi statis. Lalu, sisanya, menggambarkan tren inkonsisten; terdapat negara yang mengalami penurunan dan disusul oleh peningkatan cukup signifikan, seperti Laos, Malaysia, Vietnam, dan Thailand.

Meski begitu, patut diingat bahwa budaya BL sendiri mulai merebak di Thailand pada tahun 2007 (bersamaan dengan munculnya film dengan genre terkait). Sehingga, apabila grafik dilihat dimulai dari periode 2009-2013, maka hanya Singapura dan Myanmar-lah yang menunjukkan pergerakan menurun. Walaupun tidak dapat dikatakan bahwa pergerakan terjadi sepenuhnya akibat populernya kultur BL, preposisi bahwa kultur BL tetap memainkan peranan dalam pergerakan tersebut tidak dapat disalahkan; hanya signifikansinya saja yang belum dapat dipastikan. Setidaknya, kultur BL berhasil menunjukkan hubungan korelatif melakukan penetrasi ke hampir seluruh negara-negara tetangganya dan terjadi peningkatan penerimaan terhadap komunitas LGBTQ+ pada periode berikutnya. Sehingga, memang patut diakui bahwa diperlukan studi lanjutan terhadap tulisan ini, terutama dengan mengandalkan metode regresi yang dapat menunjukkan hasil konkret kausatif antara variabel independen kultur BL dengan variabel dependen penerimaan terhadap komunitas LGBTQ+.

\section{Kesimpulan}

Meninjau proses globalisasi dari studi kasus kultur Boys' Love (BL) Thailand, dapat dilihat bahwa kultur tersebut memiliki dampak cukup signifikan bagi masyarakat di sana serta di negara-negara Asia Tenggara dalam proses penerimaan LGBTQ+ sebagai fenomena baru. Hal tersebut dapat muncul ketika kita melihat korelasi antara semakin intensnya kultur BL dengan statistik penerimaan terhadap komunitas LGBTQ+ dari tahun ke tahun. Terdapat korelasi positif seiring dengan meningkatnya penetrasi kultur BL dari Thailand ke negara-negara tetangganya.

Namun, perbedaan geografis dan kondisi masyarakat (termasuk di dalamnya perihal keyakinan) menimbulkan berbagai macam respon dan perspektif masyarakat terkait fenomena ini. Terkhusus di Asia Tenggara, Thailand, sebagai negara yang mengenalkan kultur BL dalam bentuk tayangan hiburan, ia pun berhasil menjadi penggagas sikap toleransi terhadap kaum LGBTQ+. Akan tetapi, hal ini belum berlaku secara seutuhnya bagi sebagian negara Asia Tenggara. Walaupun penggemar drama bergenre BL hampir mencapai empat juta orang di Asia Tenggara, nyatanya stigma negatif terkait kaum LGBTQ+ masih ada dan berkembang di tengah masyarakat. Rasanya, pengaruh signifikan hanya dirasakan masyarakat yang memang mampu mengakses tayangan BL tersebut. Oleh karena itu, dibutuhkan langkah yang lebih konkret untuk memastikan posisi dan meningkatkan pengaruh kultur BL terhadap pembentukan persepsi masyarakat pada LGBTQ+, misalnya dengan menormalisasi tayangan BL atau kolaborasi antarstakeholder.

Meski begitu, dengan adanya kasus Thailand mengenai bagaimana terdapat pengakuan serta penerimaan terhadap komunitas LGBTQ + secara bertahap, bukan tidak mungkin negara-negara lain di Asia Tenggara menjadi seperti itu. Sebagaimana yang dipaparkan dalam teori queer, gender merupakan konstruksi sosial yang dapat didekonstruksi dan juga direkonstruksi, sesuai dengan kondisi masyarakat yang berlaku pada saat itu. Selain itu, heteroseksualitas juga bukan merupakan sifat natural yang absolut 
pada diri manusia; nyatanya, terdapat fluiditas dalam orientasi seksual manusia. Hal tersebut pun tercerminkan dalam masyarakat dan negara Thailand, yang notabene merupakan salah satu monarki tertua di dunia serta kental akan kebudayaan tradisional, dapat bergerak dari opresi masif menuju inklusivitas terhadap gender-gender lain, selain laki-laki dan perempuan. Sehingga, "hanya" dibutuhkan gerakan sosial-politik-budaya pada negara-negara tersebut untuk mampu mendekonstruksi serta merekonstruksi pemahaman berupa gender-gender dan seksualitas yang ada di masyarakat negara-negara Asia Tenggara.

Selain itu, adanya persebaran kultur BL beserta implikasinya terhadap penerimaan komunitas LGBTQ+ sendiri kerap dipandang sebagai dampak sosial-budaya dari globalisasi. Bahkan, beberapa secara spesifik menyampaikan bahwa penerimaan tersebut merupakan bentuk imperialisme sosial-budaya Barat atau westernisasi. Akan tetapi, para peneori queer dan juga aktivis global queer menolak akan klaim "liar" tersebut dan menyebutnya sebagai pernyataan yang merendahkan. Pada kenyataannya, tidak seluruh peradaban non-Barat mengikuti kategorisasi gender yang dibawakan oleh Barat, baik yang klasik (binerik), atau pun yang kontemporer. Layaknya pada studi kasus Thailand, terdapat identifikasiidentifikasi gender dan seksualitas lain yang unik serta nyaris tidak dapat ditemukan pada belahan dunia lain. Ditambah lagi dengan pemahaman lokal Thailand terhadap gender dan seksualitas yang umumnya berbeda dengan Barat, yang mana Barat membuat istilah "gender" dan "seksualitas" sebagai hal yang terpisah. 
101 Yasmin Nur Habibah, Januar Aditya Pratama, Mesagus Muhammad Iqbal | Globalisasi dan Penerimaan LGBTQ+ di ASEAN: Studi Kasus Budaya Boys' Love di Thailand

\section{Daftar Pustaka}

\section{Buku}

Lewis, H. (2016). The Politics of Everybody: Feminism, Queer Theory, and Marxism at the Intersection. London: Zed Books.

Sullivan, N. (2003). A Critical Introduction to Queer Theory. New York: New York University Press.

\section{Jurnal}

Adihartono, W., \& Jocson, E. U. (2020). A Comparative Analysis of the Status of Homosexual Men in Indonesia and Philippines. Journal of Southeast Asian Human Rights, 4(1), 271-305. DOI:10.19184/jseahr.v4i1.12810

Altman, D. (1996) Rupture or Continuity? The Internationalization of Gay Identities. Social Text, 48, $77-$ 94. DOI: $10.2307 / 466787$

Baudinette, T. (2019). Lovesick, The Series: Adapting Japanese 'Boys Love' to Thailand and the Creation of a New Genre of Queer Media. South East Asia Research, 27(2), 115-132. DOI:10.1080/0967828X.2019.1627762

Chokrungvaranont, P. dan Tiewtranon, P. (2004). Sex Reassignment Surgery in Thailand. Journal of the Medical Association of Thailand, 87(11). Diakses 11 Januari 2021, dari https://www.researchgate.net/publication/7910718_Sex_reassignment_surgery_in_Thailand

Collins, A. (2008). A people-oriented ASEAN: A door ajar or closed for civil society organisations? Contemporary Southeast Asia, 30(2), 313-331. DOI: 10.1335/CS30-2G

Flores, A. R. (2019). Social Acceptance of LGBT People in 174 Countries. Williams Institute UCLA School of Law. https://williamsinstitute.law.ucla.edu/wp-content/uploads/Global-AcceptanceIndex-LGBT-Oct-2019.pdf

Hamilton, A. (2001). Genders and Sexualities in Modern Thailand. SOJOURN: Journal of Social Issues in Southeast Asia, 16(2), 331. Diakses 11 Januari 2021, dari https://go.gale.com/ps/anonymous?id=GALE\%7CA79663153\&sid=googleScholar\&v=2.1\&it=r $\&$ linkaccess $=$ abs $\&$ issn $=02179520 \& p=A O N E \& s w=w$

Jackson P. A. (2000) An Explosion of Thai Identities: Global Queering and Re-Imagining Queer Theory. Culture, Health \& Sexuality, 2(4), 405-424, DOI: 10.1080/13691050050174422 
102 Yasmin Nur Habibah, Januar Aditya Pratama, Mesagus Muhammad Iqbal | Globalisasi dan Penerimaan LGBTQ+ di ASEAN: Studi Kasus Budaya Boys' Love di Thailand

Jagose, A. (2009). Feminism's Queer Theory. Feminism \& Psychology, 19(2), 157-174. DOI: $10.1177 / 0959353509102152$

Kornak, J. (2015). Queer as a Political Concept. Gender Studies, University of Helsinki. Diakses 10 Januari 2021, dari https://core.ac.uk/download/pdf/33732782.pdf

Ocha, W. (2012). Transsexual Emergence: Gender Variant Identities in Thailand. Culture, Health \& Sexuality, 14(5), 563-575. DOI: 10.1080/13691058.2012.672653

Ojanen, T. T. (2009). Sexual/Gender Minorities in Thailand: Identities, Challenges, and Voluntary-Sector Counseling. Sex Res Soc Policy, 6(2). 4-34. DOI: 10.1525/srsp.2009.6.2.4

Prasannam, N. (2019). The Yaoi Phenomenon in Thailand and Fan/Industry Reaction. Plaridel Journal, 16(2), 63-89. Diakses 10 Januari 2021, dari http://www.plarideljournal.org/wpcontent/uploads/2019/12/2019-02-Prasannam.pdf

Rudy, K. (2000). Queer Theory and Feminism. Women's Studies, 29(1), 195-216. DOI: $10.1080 / 00497878.2000 .9979308$

Tyas, I. (2019). Upaya Transnational Advocacy Networks dalam Mendorong Legalisasi LGBT Rights di Thailand. Jurnal Hubungan Internasional, 8(1), 61-73. DOI: 10.18196/hi.81145

Wilkinson, C., Gerber, P., Offord, B., \& Langlois, A. J. (2017). LGBT Rights in Southeast Asia: One Step Forward, Two Steps Back? IAFOR Journal of Asian Studies, 3(1), 5-17. Diakses 10 Januari 2021, dari http://iafor.org/archives/journals/iafor-journal-of-asian-studies/10.22492.ijas.3.1.01.pdf

\section{Situs Daring}

Chen, D. (2020). LGBTQ support lends 'new taste' to Thai Politics. The Jakarta Post: https://www.thejakartapost.com/seasia/2020/11/23/lgbtq-support-lends-new-taste-to-thai-politics.html (Diakses 11 Januari 2021).

Guzman, C. (2020). Boys' Love: The Gay Romance TV Genre Taking Over Southeast Asia. VICE: https://www.vice.com/en/article/qj4k55/boys-love-tv-asia-trend-lgbtq-2gether (Diakses 11 Januari 2021).

Hogenboom, M. (2015). Are There Any Homosexual Animal? $B B C$ : http://www.bbc.com/earth/story/20150206-are-there-any-homosexual-animals (Diakses 10 Januari 2021).

Koaysomboon, T. (2020). Everything You Need to Know about Thailand's Thriving Boys Love Culture. Timeout: https://www.timeout.com/bangkok/lgbtq/thai-boys-love-culture (Diakses 10 Januari 2021). 
103 Yasmin Nur Habibah, Januar Aditya Pratama, Mesagus Muhammad Iqbal | Globalisasi dan Penerimaan LGBTQ+ di ASEAN: Studi Kasus Budaya Boys' Love di Thailand

Rastati, R. (2020). Naiknya Thai Pop Culture dan Masa Depan Indonesian Pop (Indo Pop). LIPI: https://pmb.lipi.go.id/naiknya-thai-pop-culture-dan-masa-depan-indonesian-pop-indo-pop/ (Diakses 10 Januari 2021).

Regan, H. dan Olarn, K. (2020). Thailand Could Become the First Southeast Asian Country to Legalize Same-Sex Civil Partnerships. CNN: https://edition.cnn.com/2020/07/09/asia/thailand-same-sexunion-bill-intl-hnk/index.html (Diakses 10 Januari 2020).

UNDP (2013). Being LGBT in Asia: Thailand Country Report. Refworld: https://www.refworld.org/pdfid/54ed82784.pdf (Diakses 10 Januari 2021).

Watson, J., dan Jirik, K. (2018). Boys' Love: The Unstoppable Rise of Same-Sex Soapies in Thailand. $A B C: \quad$ https://www.abc.net.au/news/2018-06-16/boys-love-same-sex-dramas-inthailand/9874766\#: :text=In\%20recent\%20years\%20the\%20genre,normal\%20in\%20Thai\%20po p\%20culture. (Diakses 10 Januari 2021).

Wira, N. N. (2020). Rainbow-Colored Thai Dramas That Deserve Your Attention. The Jakarta Post: https://www.thejakartapost.com/life/2020/07/17/rainbow-colored-thai-dramas-that-deserve-yourattention.html (Diakses 10 Januari 2021).

Yukari, F. (2020). The Evolution of "Boys' Love" Culture: Can BL Spark Social Change? Nippon: https://www.nippon.com/en/in-depth/d00607/ (Diakses 10 Januari 2021).

Yuqiao, J. (2020). Thai BL Drama Sweeps China, Improving Cultural Communication between Countries. Global Times: https://www.globaltimes.cn/content/1181965.shtml (Diakses 10 Januari 2021). 